\title{
POTENSI WISATA ALAM AIR TERJUN AIK PENYABER DESA KEPOSANG
}

\author{
Oktarina ${ }^{1}$ Angela Listin2, Firnanda ${ }^{3}$, Laras Ariska ${ }^{4}$, Lola Anjas Fani ${ }^{5}$, Nera $^{6}$, Rina \\ Safitri $^{7}$, Sadita ${ }^{8}$, Sarbeni ${ }^{9}$, Septian Dwi Puja ${ }^{10}$ \\ Pendidikan Guru Sekolah Dasar,Fakultas Keguruan Ilmu dan Pendidikan \\ Universitas Muhammadiyah Bangka Belitung \\ Email : oktarina@unmuhbabel.ac.id
}

\begin{abstract}
ABSTRAK
Objek wisata Air Terjun Penyaber atau biasanya masyarakat lokal menyebutnya Aik Penyaber berada di desa Keposang Kecamatan Toboali, berada didaerah perbukitan muntai dan masuk dalam kawasan hutan produksi menjadikan objek wisata ini agak sulit berkembang. Objek wisata Aik Penyaber ini secara mitos berarti air yang sudah ditawarkan dari segala hal buruk, penyaber dalam bahasa lokal atas kata dasar taber dan saat ini kepercayaan itu masih dipercayai. Metode dalam penelitian ini dengan menggunakan teknik pengumpulan data seperti survey ke lapangan secara langsung, dan wawancara dengan tokoh budaya Kendala yang dihadapi seperti akses menuju lokasi, penelitian dilakukan untuk mengembangkan dan mengangkat wisata alam yang ada didaerah Keposang ini agar lebih dikenal masyarakat luar karena pada masyarakat Keposang sendiri sudah mengetahui keberadaan Air Terjun ini. Wisata Air Terjun Penyaber mempunyai dua potensi, potensi alam yang berupa pemandangan yang bagus, kualitas udara yang baik dan potensi buatan berupa gazebo yang merupakan tempat untuk beristirahat. Dengan adanya penelitian ini diharapkan eksistensi wisata Air Terjun ini makin terangkat dan lebih berkembang semakin baik.
\end{abstract}

Kata Kunci : Air Terjun Penyaber, Keposang, Toboali, Wisata Alam

\begin{abstract}
ABSTRACK
The tourist attraction of Penyaber Waterfall or usually local people call it Aik Penyaber is located in the village of Keposang Toboali District, located in the area of Muntai hills and included in the production forest area makes this tourist attraction rather difficult to develop. This Aik Penyaber attraction mythically means water that has been offered from all bad things, penyaber in the local language on the basic word taber and today that belief is still believed. The method in this research uses data collection techniques such as surveying the field directly, and interviews with Keposang village cultural figure. Obstacles faced such as access to the location, research is carried out to develop and lift the existing natural tourism in this area keposang to be better known to the outside community because in the community Keposang itself already know the existence of this waterfall. Penyaber Waterfall tourism has two potentials, natural potential in the form of good scenery, good air quality and artificial potential in the form of gazebos that are places to rest. With this research, it is expected that the existence of this waterfall tourism will be raised and more developed the better.
\end{abstract}

Keywords: Penyaber Waterfall, Keposang,Toboali,Natural Tourism

\section{PENDAHULUAN}

Pariwisata menurut Wahid (2015), pariwisata adalah perjajanan dari satu tempat ke tempat lain, bersifat sementara, dilakukan perorangan maupun kelompok, sebagai usaha mencari keseimbangan atau keserasian dan kebahagiaan dengan lingkungan hidup dalam dimensi sosial, budaya, alam, dan 
ilmu. Pariwisata merupakan suatu kebutuhan sebagai kegiatan melepas penat dari kesibukan dan rutinitas sehari-hari. Menurut Ismayanti (2010), berdasarkan jenis-jenis objek wisatanya, pariwisata dibagi menjadi beberapa jenis salah satunya adalah Wisata Cagar Alam (Ecotourism). Merupakan wisata yang banyak dikaitkan dengan kegemaran akan keindahan alam, Kesegaran hawa di pegunungan, keajaiban hidup binatang (margasatwa) yang langka, serta tumbuhtumbuhan yang jarang terdapat di tempat-tempat lain.

Keunikan sumber daya alam air terjun yaitu air terjun, flora dan fauna. Banyaknya sumber daya alam yang menonjol yaitu bebatuan, flora dan fauna serta gejala alam. Kebersihan objek wisata yang tidak dipengaruhi oleh Kegiatan industri, jalan ramai, pemungkiman penduduk, sampah, vandalism (coretcoretan) dan pencemaran lainnya.Keamanan objek wisata seperti tidak ada arus berbahaya, tidak ada pengambilan pasir, tidak ada pencurian, tidak ada penyakit berbahaya, tidak ada kepercayaan yang mengganggu. Kenyamanan objek wisata seperti udara yang bersih dan sejuk, bebas dari bau, bebas dari kebisingan dan bagaimana pelayanan terhadap pengunjung. (Hasmida \& Sudhartono, 2016)

Wisata yang disebut Air Terjun Penyaber masuk dalam jenis pariwisata cagar alam dimana terdapat keindahan alam dari perbukitan, terdapat tumbuhan langka seperti tanaman Pelawan (tristaniopsis merguensis) yang menjadi jenis tanaman langka untuk saat ini. Air penyaber sebutan oleh masyarakat lokal terletak di Desa Keposang, Kecamatan Toboali, Kabupaten Bangka Selatan. Penyebutan itu sendiri mempunyai makna khusus "penyaber"berarti sudah ditawarkan atau bahasa Bangka "sudah di taber" yang bermakna air yang mengalir dari bebatuan itu sudah tawarkan dari hal-hal buruk. Aik Penyaber ini merupakan salah satu objek wisata alam yang ada di Desa Keposang. Dengan adanya kemajuan pariwisata otomatis perekonomian daerah setempat ikut maju, pariwisata yang maju terbukti mampu memberikan dampak yang baik bagi kehidupan ekonomi masyarakat karena dengan kemajuan pariwisata bisa menciptakan peluang kerja , membantu pendapatan masyarakat local selain itu kemajuan pariwisata juga meningkatakan pembangunan daerah pariwisata. Dengan demikian tim pelaksana KKN (Kuliah Kerja Nyata) Universitas Muhammadiyah Bangka Belitung melakukan program berupa pembersihan dan pengelolaan wisata Aik Penyaber Desa Keposang, Toboali agar perkembangan wisata lokal ini semakin baik, dan lebih dikenal masyarakat luar.

Menurut Fandeli (2002) wisata adalah perjalanan atau atau sebagai dari bagian tersebut dilakukan secara sukarela serta bersifat sementara untuk menikmati objek dan daya tarik wisata. Awalnya perjalanan wisata sering berkaitan dengan perjalanan ibadah,eksplorasi, geografis, ilmu pengetahuan studi antopologi dan budaya serta keinginan untu melihat keindahan bentang alam. Pengembangan pariwisata adalah usaha secara sadar dan terencana untuk memperbaiki objek wisata yang akan dipasarkan . pengembangan tersebut meliputi perbaikan objek dan pelayanan kepada kepada wisatawan semenjak berangkat hingga pulang kembali ketempat semula. Santoso (2009).

Daya tarik wisata adalah segala sesuatu yang memiliki keunikan, keindahan dan nilai berupa keanekaragaman kekayaan alam, budaya, dan hasil buatan manusia yang jadi sasaran atau tujuan kunjungan wisata (Yoeti, 1996). Jadi yang dimaksud daya tarik wisata adalah semua hal yang menjadian objek wisata tersebut menarik minat pengunjung. (Firawan \& Suryawan, 2016) 
Dengan adanya penelitian dan kegiatan ini diharapkan keberadaan wisata ini lebih terangkat dan dikenal keluar daerah sehingga dengan banyaknya wisatawan yang datang maka perkembangan kawasan wisata, ekonomi warga lokal ikut membaik

\section{METODE}

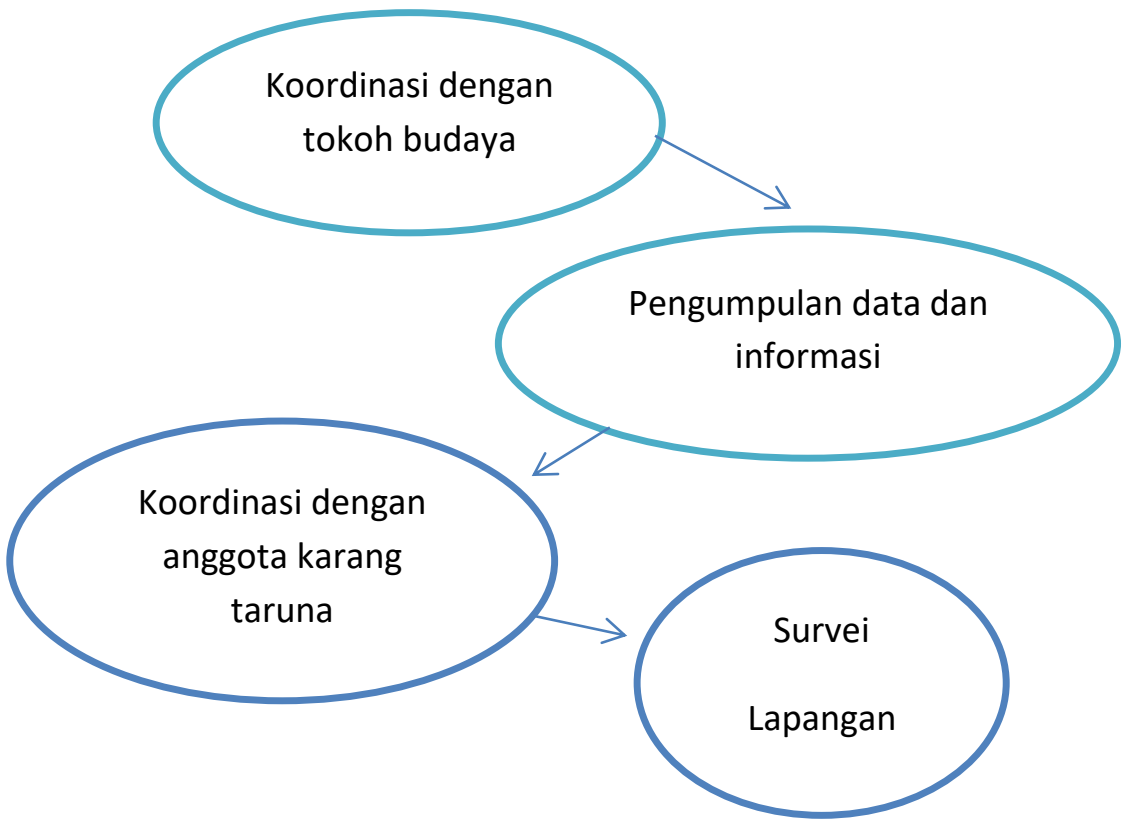

Gambar 1. Tahap Pelaksanaan Kegiatan

Penelitian ini dilakukan dengan cara mendatangi kawasan secara langsung di desa Keposang, Kecamatan Toboali, Kabupaten Bnagka Selatan. Penelitian ini dilakukan dengan cara survey lapangan dan wawancara pada tokoh budaya desa Keposang. Dengan ini kami sebagai peneliti sekaligus wisatawan ingin mengetahui potensi apa yang dimiliki dari Air Terjun Penyaber dan apa yang menjadi daya tarik pengunjung terhadap Air Terjun Penyaber itu sendiri.

\section{HASIL DAN PEMBAHASAN}




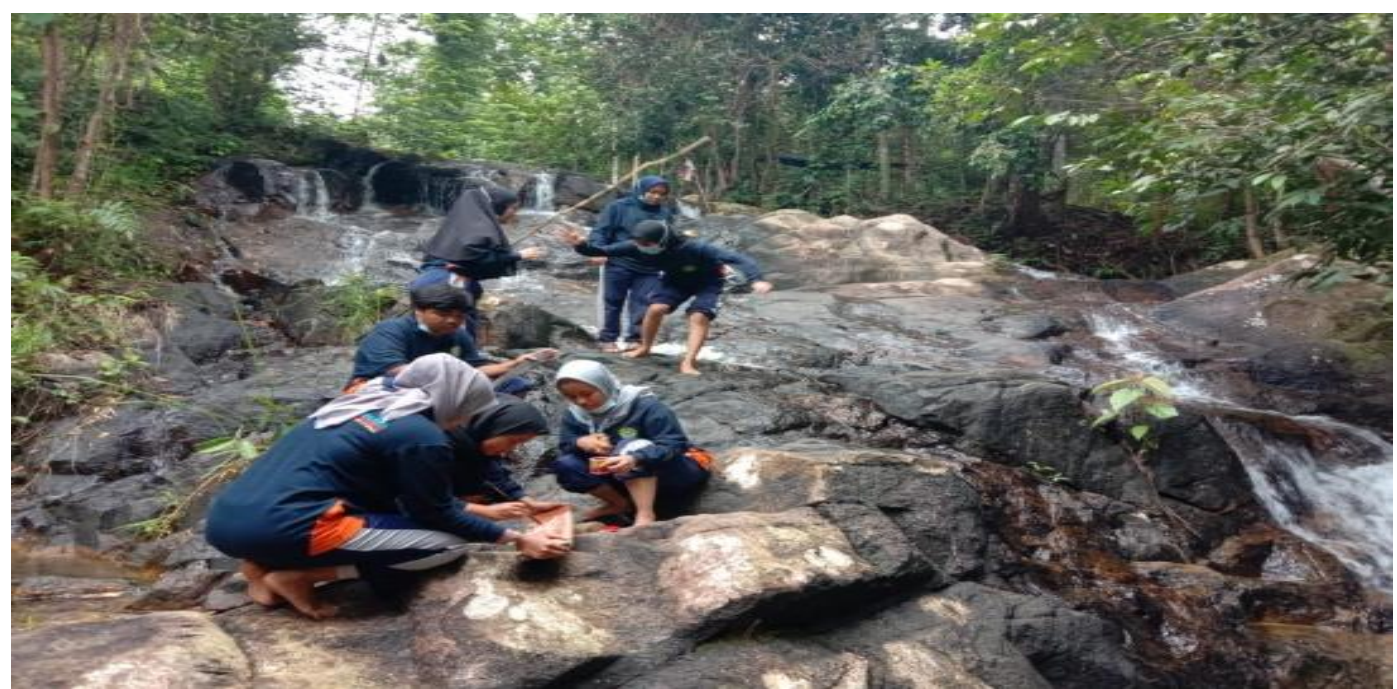

Gambar 2. Pelaksaan Kegiatan

Wisata Air Terjun Penyaber yang berada di Desa Keposang mempunyai daya tarik tersendiri dan dikatakan layak dalam beberapa aspek akses yang mudah ditempuh dengan alokasi waktu kurang lebih 30 menit dengan berjalan kaki dan sekitar 15 menit jika membawa kendaraan roda dua. Air Terjun Penyaber berada di perbukitan Muntai dengan ketinggian kurang lebih $300 \mathrm{mpl}$. Air Terjun Penyaber mempunyai sarana yang cukup baik seperti tersedianya tempat sampah dan tanda penunjuk jalan, mengenai akses memang tidak bisa terlalu dikembangkan mengingat air terjun ini berada dihutan produksi.

Air Terjun Penyaber sudah banyak diketahui oleh masyarakat setempat tapi untuk masyarakat luar daerah Keposang masih kurang mengetahui keberadaan wisata alam ini, perlu ada usaha untuk memperkenalkan dan mempromosikan wisata ini sehingga diharapkan akan menarik wisatawan dan membawa keuntungan bagi pihak yang bersangkutan untuk memperbaiki fasilitas Air Terjun Penyaber. Beberapa hal mungkin yang perlu diperhatikan adalah mempertahankan potensi alam yang natural dengan memasang tanda - tanda larangan - larangan untuk pencemaran dan sign untuk tidak membuang sampah sembarangan. Upaya lainnya adalah dengan menyediakan tempat sampah di beberapa titik pada objek wisata (Yuni, 2011) Dengan membaik dan berkembangannya daya tarik wisata Air Terjun Penyaber ini diharapkan dapat mendorong pembangunan wisata ini serta memahami potensi yang bisa dikembangkan. 


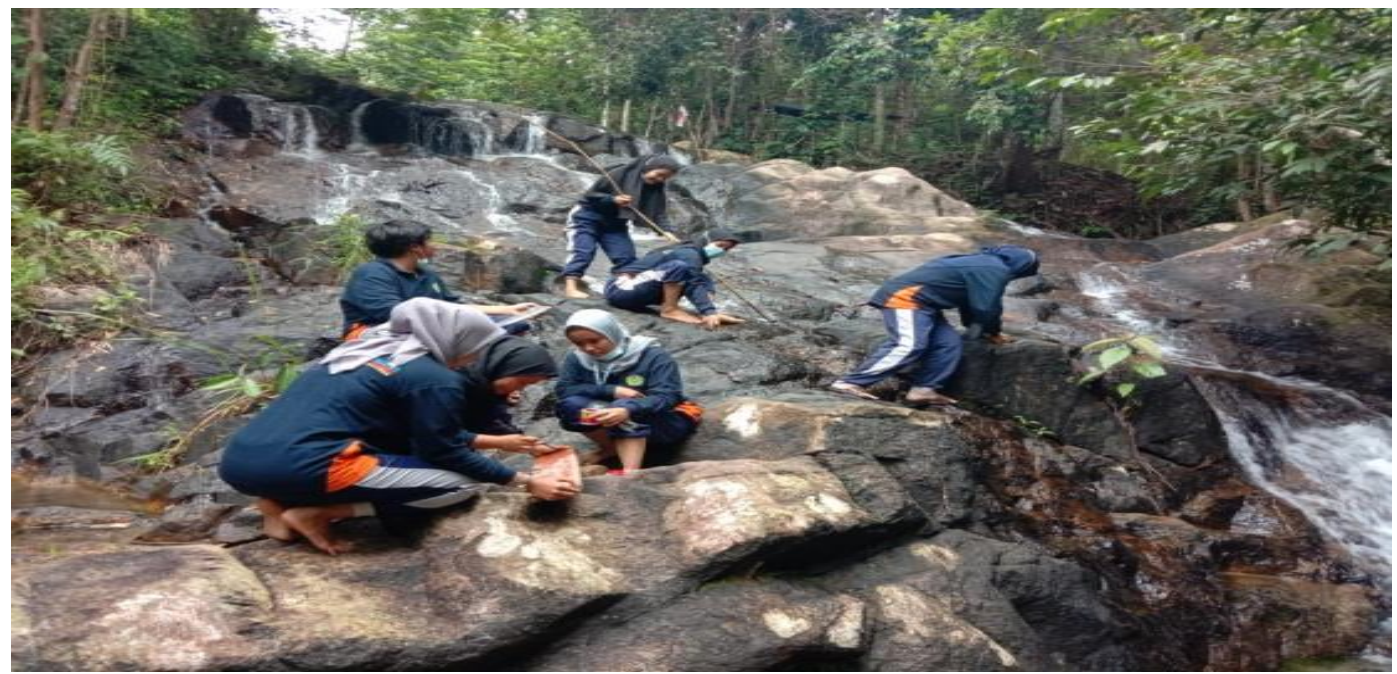

Potensi dari Air Terjun Penyaber mempunyai potensi seperti

1. Potensi Alam, Air Terjun Penyaber memiliki pemandangan alam yang ini, terletak diperbukitan membuat wisatawan merasakan perbedaan suhu udara yang sejuk dan kualitas udara yang baik karena suasana disekitar air terjun banyak terdapat pepohonan tinggi. Selanjutnya adalah

2. Potensi Buatan

kawasan wisata Aur Terjun Penyaber dapat dikembangkan dengan didirikannya pondok atau gazebo untuk persinggahan dan tempat istirahat, namun gazebo atau pondok belum tersedia disini.

\section{SIMPULAN}

Potensi dari wisata Air Terjun Penyaber yang dapat dikembangkan adalah potensi alam berupa pemandanganalam yang masih asri dengan adanya beberapa flora dan fauna yang masih langka seperti pohon pelawan, pohon jati dan beberapa jenis kupu-kupu langka yang bisa dijadikan sebagai sarana belajar dari alam. dan potensi buatan. Seperti perlunya pembangunan gazebo, spot foto yang menarik. Apabila kawasan wisata ini semakin banyak dikunjungi wisatwan maka akan semakin baik perkembangan potensi,eksistensi kawasan wisata Air Terjun

Penyaber.

\section{DAFTAR PUSTAKA}

Darmadjati, R. S. 2001. latilah-Istilah Dunia Pariwisata.Jakarta : Pradnya Paramitha.

Fandeli, C . 2011. Dasar-dasar Manajemen Kepariwisataan Alam. Yogyakarta, Liberty.

Firawan, I. G. N. F., \& Suryawan, I. B. (2016). Potensi Daya Tarik Wisata Air

Terjun Nungnung Sebagai Daya Tarik Wisata Alam. Jurnal Destinasi

Pariwisata, 4(2), 92. https://doi.org/10.24843/jdepar.2016.v04.i02.p15 Hasmida, \& Sudhartono, A. (2016). Pariwisata juga dapat meningkatkan tarif. Hakim , L . 2004. Dasar-dasar Ekowisata, Bayumedia Publishing, Jawa Timur. Ismayanti. 2010. Pengantar Pariwisata. Jakarta: Gramedia Widisarana.

Santoso. 2009, Pariwisata dan Pengembangan Objek Wisata Pntai Klayar Di Kabupaten Pacitan. Laporan Tugas Akhir Program Studi Diploma III Usaha 
Perjalanan Wisata Fakultas Sastra dan Seni Rupa, Universistas Sebelas Surakarta.

Wahid, Abdul. 2015. Strategi Pengembangan Wisata Nusa Tenggara Barat Menuju Destinasi Utama Wisata Islami. Yogyakarta: UMY.

Yuni, H. K. (2011). Strategi Pengembangan Air Terjun Tegenungan Sebagai Daya Tarik Wisata Alam Di Desa Kemenuh, Gianyar Bali. Sosial Dan Humaniora, 6(3), 169-184.

Hadi Kurniawanto, Hafidz Hanafiah, \& Ardi Hidayat. (2020). PENGEMBANGAN UMKM BONTOT SALMINAH SEBAGAI KULINER KHAS KOTA SERANG MENUJU ERA INDUSTRI 5.0. Jurnal Abdimas Bina Bangsa, 1(1), 1-14. doi:10.46306/jabb.v1i1.8

Pamungkas, M. D., \& Fadhilah Rahmawati. (2020). WORKSHOP PENGGUNAAN SOFTWARE GEOGEBRA SEBAGAI MEDIA PEMBELAJARAN MATEMATIKA BAGI GURU SD/MI. Jurnal Abdimas Bina Bangsa, 1(2), 176-185. doi:10.46306/jabb.v1i2.18 